\title{
NOTAS PRELIMINARES SOBRE O CARÁTER DA FORMAÇÃO TERRITORIAL BRASILEIRA (*)
}

\author{
Wanderley M. da Costa (*\%)
}

\section{Introdução}

Este trabalho pretende examinar alguns aspectos da relação entre o caráter e as etapas do desenvolvimento capitalista no Brasil, aqui entendido como capitalismo retardatário, e as formas gerais e específicas de sua realização em dados espaços do território brasileiro. O objeto de análise, portanto, restringe-se, de um lado, às particularidades do capitalismo neste país em suas determinações mais gerais (os padrões de acumulação de capital), e de outro, à expressão territorial desses processos.

Um enfoque dessa natureza aponta para a seguinte hipótese: no âmbito das relações de produção capitalistas, o capital não se realiza linearmente através do tempo e do espaço. A desigualdade, portanto, é elemento intrínseco do seu desenvolvimento, o que implica em desiguais acumulação e distribuição das riquezas acumuladas, quer entre as classes sociais de que se compõe, quer entre os diferentes lugares de que se apropria. Isto ao nível da lei geral. As particularidades manifestam-se em vários outros processos, como por exemplo, na tendência à especialização na atividade industrial -que se expressa nas diferenças salariais e numa dada divisão social do trabalho. Além disso, numa particular divisão territorial do trabalho, o que implica em desiguais dotações de recursos entre as áreas afetas à produção, circulação e consumo. Também é notória a compulsão do capital em concentrar-se, tanto ao nível de uma determinada classe social, mas igualmente, quanto ao nível de empresas, estabelecimentos e lugares. Fica difícil, portanto, o exame do tema proposto sem considerar estas três manifestações histórico-concretas do modo de produção capitalista: desigualdade, que exige especialização e concentração.

Com relação à expressão territorial dos modos de produção, M. Santos diz: "O espaço portanto, é um testemunho; êle testemunha um momento de um modo de produção pela memória do espaço construído, das coisas fixadas na paisagem criada" (SANTOS, 1978 p. 138). O mesmo autor afirma que esta relação (geral) pode apresentar variações significativas, como é o caso dos países sub-desenvolvidos, em que, segundo ele, as "macrocefalias" comuns em tais países, seriam o resultado dos "progressos tecnológicos" e das "tendências à concentração"

Tentaremos verificar estas articulações no âmbito específico dos fenômenos que vamos analisar para o caso brasileiro.

\section{Capitalismo Tardio e a Herança Colonial}

E fora de dúvida que a maior contribuição teórica (no Brasil) para a discussão deste tema,

(*) - Artigo apresentado como trabalho de aproveitamento ao Curso "Problemas de G. das Indústrias" ministrado pela Profa Lea Goldentein, no $2^{\circ}$ semestre de 1979 , em nível de Pós-Graduação. Trabalho recebido para publicação em outubro de 1980 .

(**) - Auxiliar de Ensino do Departamento de Geografia - FFLCH - USP. 
deve-se a João Manuel Cardoso de MELLO (1975), que inaugura um vigoroso repensar da economia brasileira, no sentido de captar a essência contraditória do desenvolvimento capitalista neste país. Ao fundir, pela dialética, determinações históricas e econômicas, ele evita tanto o economicismo quanto o historicismo, o que resulta numa verdadeira teoria geral de interpretação do Brasil.

Ao examinar as teorias cepalinas de centro-periferia, o autor comenta: "A propagação desigual do processo técnico (que é visto como a essência do desenvolvimento econômico) traduz-se, portanto, na conformação de uma determinada estrutura da economia mundial...". Segundo êle, de um lado as "economias industrializadas" e de outro, a periferia, "economias exportadoras de produtos primários". Mais adiante, ainda com relação às teorias cepalinas, comenta que para estas, a possibilidade de emancipação dos países periféricos estaria na industrialização, momento em que estes países se constituiriam enquanto nações, libertandose do jugo dominador. Diz, porém, que tais teorias foram desmentidas pela realidade, pois a industrialização ou se "abortara" ou, nos casos em que teve "êxito, não eliminara tal dominação nem a miséria. Segundo êle, é aí que surgem as teorias da dependência, como recurso teórico de que lança mão as análises cepalinas posteriores. É a partir destas críticas que o autor cunha a expressão "Capitalismo Retardatário", como teoria mais ampla, capaz de superar os equívocos cepalinos.

A idéia central de sua interpretação é a de distinguir uma economia primário-exportadora de uma economia colonial, enquanto momentos históricos específicos do desenvolvimento capitalista em paises periféricos. Capitalismo retardatário sim, pois que este surge apenas no momento em que as economias exportadoras organizaram-se com o trabalho assalariado. Apenas aí que se deu a passagem de uma economia colonial para uma economia primário-exportadora-capitalista (MELLO, 1975, p. 26).

Com relação ao nosso problema específico, podemos dizer que o Brasil de economia colonial, assim como outros países, caracterizou-se fundamentalmente pela presença da grande produção agrária de exportação, que em sua essência buscava o máximo lucro em mínimos custos possíveis, o que explica a presença do trabalho compulsório, de uma prática agrícola extensiva, cujo limite de produtividade era dado pela fertilidade absoluta do solo, disponibilidade de terras e pela capacidade física do escravo. A busca do mínimo custo explica ainda a localização da exploração numa estreita mas longa faixa de terras próximas ao litoral, o que evitava custos adicionais de transporte terrestre.

Do ponto de vista da organização do território, um dos resultados dessa exploração foi um padrão colonial de urbanização, em que os centros urbanos mais destacados, aqueles de função portuária, comercial e administrativa, apresentavam ínfima ou nenhuma relação entre si, já que voltados em grande parte aos fluxos intensos com a metrópole européia. Isto, sem mencionar os fracos fluxos com o interior, excetuando-se aí o comércio de carne oriunda do sertão. Destaque-se ainda o fato de que o dinamismo econômico da colônia centrava-se nas grandes propriedades, o que constituía fator de estagnação das cidades.

Estes fatos representam, de certo modo, a concentração territorial de uma particular exploração econômica, qual seja, a colônia de exploração, cujo objetivo era o da exploração imediata, o que impediu o assentamento efetivo de população, uma integração territorial e mecanismos endógenos de acumulação de capital, causas últimas do prolongado atraso econômico e social do país (PRADO JR., 1973, especialmente "Sentido da Colonização").

\section{Economia Exportadora Capitalista e a In- ternalização da Acumulação}

Para J.M.C. de Mello, assim como para C. Prado Jr. e outros autores, a passagem para uma economia exportadora capitalista no Brasil é determinada em última instância pela crise do sistema colonial, que tem por base, entre outras causas, a crise de mão de obra (escrava), o esgotamento da economia mineira, a queda do exclusivo metropolitano e a formação do Estado Nacional. 
A mudança significativa no padrão de acumulação de capital deveu-se em grande parte aos constantes impulsos do chamado "capital mercantil nacional", já que este transformou-se, através das casas comissárias, no principal agente econômico estimulador da expansão agro-exportadora subseqüente: a produção cafeeira no sudeste do país. Mesmo levando-se em conta que parte do processo de acumulação ainda era feito no exterior, além de que, o sucesso do empreendimento dependia sobremaneira da demanda externa, considera-se que é a partir desta passagem que se inaugura um verdadeiro processo de internalização do excedente auferido na atividade mercantil, que se constituirá em fator primordial para os mecanismos endógenos de acumulação de riquezas.

Para que fique clara a relação entre esta nova etapa do capitalismo no Brsil e o novo padrão territorial de localização e exploração, faz-se necessário recorrer às características da exploração colonial mineira no interior do país.

É inegável que quanto à forma, o deslocamento da exploração em áreas litorâneas para o interior do país (MG, GO, MT) significou uma alteração no padrâo territorial até então vigente. Isto porque a interiorização da economia permitiu, de um lado, a anexação econômica de parcelas até então marginalizadas da exploração; de outro, dado o caráter peculiar da exploração mineira — alto valor por unidade dos produtos, pela sua raridada e pela quantidade de trabalho dispendido na produção - permitiu em pouco espaço de tempo, a instalação de uma razoável infraestrutura regional, capaz de integrar boa parte do território às áreas litorâneas (RJ, por exemplo), por vias terrestres, interiorizar a urbanização e equipar núcleos urbanos próximos e distantes da produção. Desenvolveu ainda as bases materiais para a emancipação política do país, além de, pela especificidade da exploração, transferir cada vez mais para os centros urbanos os poderes de decisão política e econômica.

Falamos acima que a interiorização da exploração significou uma mudança de forma, isto porque este processo nem refletiu e nem foi acompa- nhado por uma mudança qualitativa no padrão de acumulação, qual seja a exploração colonial. Isto não significa entretanto, que as transformações no âmbito da organização territorial, com a mineração, não tenham jogado nenhum papel nas reais mudanças posteriores a que se assistiu no país. Este raciocínio baseia-se no fato de que os momentos históricos de um modo de produção estão associados a uma objetiva e necessária expressão material (territorial) e por isso mesmo, sujeitos até a uma verdadeira sobredeterminação dos momentos anteriores materializados no espaço, capazes que são, pelo seu caráter duradouro, de interferir objetivamente nos rumos das etapas posteriores.

Em suma, a superação de uma etapa por outra, ou mesmo de um modo de produção por outro, não implica necessariamente na destruição da herança territorial. Considerando-se ser este o caso brasileiro, então a mudança a que aludimos não pode ser reduzida a uma mudança de forma.

Tentaremos agora avançar um pouco, procurando concretizar a argumentação acima.

A expansão da produção cafeeira a partir da primeira década do século passado, marcou a constituição do que se convencionou chamar de "Economia Nacional". Este processo vinculou-se a outros de natureza econômica (algum excedente da economia mineira, mão de obra escrava, participação de agentes financeiros, etc.), política (constituição do Estado Nacional) e geoeconômica. Caracterizou-se este último, em primeira instância, pela existência de condições materiais prévias (capital instalado e incorporado ao espaço), representadas pela disponibilidade de um centro urbano portuário equipado para a exportação (Rio de Janeiro), estradas (ligando o Vale do Paraíba às minas e ao litoral), centros urbanos menores ao longo do rio Paraíba; enfim, espaço construído anteriormente. Aqui, vale questionar: eram as terras do Vale do Paraíba próprias ao café, justificando assim a exploração nesta região? Parece-nos que não foi o caso. Não eram as terras (solo) próprias ao café (aliás, as "boas terras" só seriam descobertas mais tarde), mas sim, a regiāo que o era. Não foi a fertilidade ou não do solo o indutor da localização da nova ex- 
ploração, mas a posição privilegiada de uma região próxima ao Rio de Janeiro e das áreas litorâneas e dotada de uma infraestrutura mínima obtida em atividade anterior. Este fato nos induz a pensar numa localização econômica determinada objetivamente pelo espaço criado.

A expansão cafeeira posterior obedece a mecanismos similares. Esta não se fará dissociada de suportes materiais presentes no território, o que pode ser constatado pelo papel de um centro urbano como Campinas, verdadeira "boca de sertão" e centro indutor na marcha para o interior, antes mesmo do advento do trabalho livre. E esta será a tônica geoconômica das explorações subseqüentes em que, ao contrário do período colonial, as expansões agrícola, urbana, ferroviária e rodoviária, significarão um mesmo processo.

Poderíamos sintetizar esta nova tônica na exploração econômica, afirmando que a partir da produção cafeeira, o processo de constituição da "Economia Nacional" vincula-se organicamente não só à internalização da acumulação de capital, mas, simultaneamente, a uma redefinição na formação territorial do país, no sentido de que a expansão econômica será simultânea à expansão das fronteiras agrícolas e urbanas, em outras palavras, à interiorização do espaço construido.

Antecedendo a este processo, é inegável o papel jogado pelo advento do trabalho livre na extraordinária velocidade adquirida pela marcha do café a partir do final do XIX. A interiorização do plantio a partir daí, impulsionada ainda pela demanda externa favorável, pela ampliação da infraestrutura e por laços cada vez mais estreitos entre o capital produtivo e o capital financeiro, permitenos falar num verdadeiro "complexo cafeeiro".

Do ponto de vista econômico, esse será o núcleo propulsor da economia capitalista exportadora. Do ponto de vista estritamente social, aí repousarão as bases de uma sociedade moderna capitalista. Quanto ao estritamente geográfico, tal processo representou o fim de um padrão territorial de tipo colonial em que o enclave substitui a totalidade espacial. Foi somente a partir do momento em que o novo caráter do desenvolvimento econômico passou a comandar indissoluvelmente o campo e a cidade que o território adquiriu a sua plena função capitalista.

Quando a literatura especializada menciona a gestação de um mercado interno para produtos industrializados, refere-se certamente, como parte deste processo, aos novos trabalhadores assalariados ou aos novos empresários de café ou mesmo ao complexo cafeeiro em geral. Perde-se aí frequentemente a perspectiva de que são muito mais que isso: novos trabalhadores e novos empresários em novas áreas produtivas; ou ainda, novos centros urbanos integrados por novas vias de transportes, componentes fundamentais de um espaço econômico que se alarga continuamente. É esta a dimensão completa do mercado interno que se forja na economia exportadora capitalista.

A explicação destas articulações pode ser obtida ao compreender-se que, ao inserir-se plenamente nos processos endógenos da produção capitaista, o território passou a valorizar o capital empregado, tanto pelo seu valor em si (o preço do solo determinado pela fertilidade e pela localização), quanto pelas sucessivas incorporações (estatais, privadas, etc) de valor criado (expresso na intensa valorização das terras) tornando-se êle próprio capital constante e mercadoria, difenindo-se, portanto, em território exclusivamente capitalista (1).

\section{Considerações finais}

Parece-nos, assim, um tanto quanto superficial, atribuir a violenta concentração econômica do SE, e em particular de São Paulo, tão somente a um mero deslocamento do eixo econômico (com a mineração e o café), quando em realidade tratou-se de

(1) - Esta questão é tratada por Costa, W. M. e Moraes, A.C.R. em "Valor, Espaço e a Questão do Método", Temas de Ciências Humanas no 5, 1979 Ed. C. Humanas e "A Geografia e o Processo de Valorização do Espaço", inédito, mimeografado, 1980, em que os autores tentam explicitar a formação territorial sob a ótica do marxismo clássico. 
uma radical transformação, de um lado, no padrão de acumulação de capital, e de outro, nas formas particulares de desenvolvimento territorial.l A internalização/interiorização do capital permitiu ainda a estruturação de uma rede urbana hierarquiza$\mathrm{da}$, paralela e necessária às atividades produtivas, transformando velhos centros coloniais como Rio de Janeiro e São Paulo em metrópoles nacionais, capazes, pelo dinamismo de suas funções, de captar, centralizar e redistribuir parte considerável do excedente produzindo, e mais ainda, capazes de comandarem, a partir do início deste século, todos os processos modernizantes verificados no país.

A argumentação até aqui adotada pode também aplicar-se a algumas particularidades do chamado processo de industrialização do país. Alguns autores, em trabalhos recentes, têm demonstrado corretamente que a nascente indústria doméstica, desde o final do século passado, caracterizava-se exclusivamente como produtora de bens de consumo não duráveis, de trabalho intensivo, baixa absorção tecnológica e destinados em grande parte aos assalariados. Demonstraram também que esta indústria cumpria, pelo menos até 1.930 , uma dupla função no âmbito da economia exportadora capitalista: de um lado, a de suprir populações assalariadas de artigos de baixo custo e absorver excedentes de mão de obra rural, e de outro, servir de alternativa de investimentos de capitais que mantivessem o padrão de acumulação em momentos cíclicos de crise cafeeira. E desta forma, que pelo menos "horizontalmente", a pequena indústria nacional pôde crescer à sombra da exploração principal. Tal industrialização incipiente achava-se res- trita aos dois centros já mencionados. Representava, portanto, a alternativa urbana de trabalho a imigrantes e nacionais; representva também a alternativa urbana de investimentos de capitais a empresários rurais. Não estava a reboque do complexo cafeeiro, mas era parte deste. A partir do momento em que a produção cafeeira se enfraquece enquanto motor hegemônico de acumulaçãò de capital, os centros urbanos dinamizam-se, a industria inicia seu processo de verticalização, o Estado passa a tornar-se o gerente da destinação dos recursos para este setor e os empresários canalizam seus capitais mais e mais para o crescimento urbano-industrial. As indústrias pioneiras, restritas aos centros históricos destas cidades, e as novas empresas iniciam então um vigoroso processo de descentralização em direção à periferia urbana, alongam-se paralelas às vias férreas e às novas estradas de rodagem. No plano regional, surgem centros como o de Belo Horizonte, Volta Redonda, ou mais próximos das metrópoles como Campinas, Sorocaba, São José dos Campos, Santos, etc., manifestações de um amplo crescimento e de limitação de um espaço econômico de dentro para fora, que, à maneira do café, internaliza e interioriza a produção, agora industrial.

Em verdade, estes são apenas alguns apontamento de uma argumentação que deverá tornarse ampla, a ponto de poder dar conta de especificidades da formação territorial brasileira, bastante complexa para o âmbito deste pequeno trabalho. Trata-se muito mais de escolher-se um caminho, o mais coerentemente possível, mesmo conhecendo-se os possíveis riscos de desvios teóricos e práticos de uma tentativa deste t:po.

\section{BIBLIOGRAFIA CITADA}

1 - COSTA, W. M. e MORAES, A. C. R. - (1979) - Valor, espaço e a questão do método. Temas de Ciências Humanas (5), Livraria Editora Ciências Humanas, São Paulo.

$2-1-(1980)-\mathrm{A}$ Geografia e o processo de valorização do espaço. Inédito, mimeografado.
3 - MEllo, J. M. C. - (1975) - O capitalismo tardio. Ed. do autor, Campinas.

4 - PRADO JR., Caio - (1973) - Formação do Brasil Contemporâneo. Ed. Brasiliense, São Paulo.

5 - SANTOS, M. - (1978) - Por uma Geografia Nova. Ed. Hucitec, S. Paulo. 